\title{
Techno-economic assessment of small-scale renewable energy storage technologies
}

\author{
Desmond Eseoghene Ighravwe ${ }^{\mathrm{a}^{*}}$
}

${ }^{a}$ Bells University of Technology, Nigeria

\begin{tabular}{l}
\hline C H R O N I C L E \\
\hline Article history: \\
Received February 19, 2018 \\
Received in revised format: \\
August 10, 2018 \\
Accepted August 30, 2018 \\
Available online \\
August 30, 2018 \\
\hline Keywords: \\
Techno-economic requirements \\
Energy storage technology \\
PROMETHEE method \\
Fuzzy quality function deployment \\
Small-scale renewable energy
\end{tabular}

\section{Introduction}

Energy storage technology (EST) has helped to improve the balance between power generation and demand (Koohi-Kamaliab et al., 2013). Through proper EST selection, the issue of power transmission quality has been addressed by researchers and scholars (Smith et al., 2008). This technology has been broadly classified as thermal and electrical (Baker, 2008). Under electrical EST, which this study is concerned, further EST groups are potential, kinetic, and electrochemical EST (Baker, 2008). The type of EST that an environment will adopt for its energy management depends on the quantity of energy to be stored and the type of energy network (Hadjipaschalis et al., 2008; Ekman \& Jensen, 2010). For instance, fuel consumption of a renewable energy plant can be reduced through the proper selection of an EST (Singh et al., 2015; Tlig \& Rebai, 2017; Janaki et al. 2018). EST selection can be used to EST to manage hybrid energy system such as wind and diesel units (Sebastian, 2013). In Sebastian's (2013) study, they simulated the change between positive and negative loads in their study using a Ni-Cd energy storage unit. This kind of simulation will not only benefit residential buildings, but it will also improve energy management in commercial buildings (Nair \& Garimella, 2010).

\begin{abstract}
B S T R A C T renewable energy systems. The present study was able to achieve this using the results that were generated from a Preference Ranking Organisation Method for Enrichment Evaluation model, experts' and a fuzzy quality function deployment (FQFD) model. Using the FQFD techno-economic requirements importance for the selection process. The FQFD model considered system safety, availability, flexibility, reliability and effectiveness as customers' requirements, while nominal voltage, nominal discharge current, peak measured voltage,
operating cost and cost of energy were among the techno-economic requirements. During the framework application, a questionnaire was used to collect information from experts on the requirements for four ESTs were obtained from literature. The FQFD model results were incorporated into a PROMETHEE and TOPSIS models. The PROMETHEE and the TOPSIS
\end{abstract}

(C) 2018 by the authors; licensee Growing Science, Canada. 
In buildings, EST has the capacity to reduce the energy cost while improving the quality and the reliability of energy supply to buildings (Zogg et al., 2007; Divya \& Ostergaard, 2009). It has helped to improve the incorporation of the existing transmission system with renewable energy units (Shively et al. 2008). When a renewable energy source and an EST are used to address energy problems, it helps to improve the use of cleaner energy, and this will translates to environmental and economic benefits (Kaldellis et al., 2009). For instance, it has been observed that improvement in transmission cost and utilisation will be experienced when wind farms are co-located with compressed air energy storage (Denholm and Sioshansi, 2009). Also, off-load and on-peak load balancing are experienced when EST is installed in a transmission system; this creates an opportunity for energy to be purchased at a low price between these periods (Sioshansi et al., 2009). Thus, this makes the selection of EST an important matter when dealing with grid projects.

When a suitable EST is selected for a grid project, improvement in the grid reliability and efficiency will be experienced. However, consideration must be given to the associated charging efficiency of the EST (Walawalkar et al. 2007). And also the maintenance of a steady flow of electricity to target customers is another factor that needs to be considered during EST selection. This is renewable energy sources energy supply fluctuate. For example, when sunset, the maximum power that will be generated from solar-powered system systems will drop to a level that can cause power interruption. Similarly, a significant decrease in wind speed will affect a wind-powered energy system output. Beyond the issue of energy supply, solar- or wind-powered energy systems owners are interested in making a decision on the number of batteries, converter, nominal voltage and peak measured voltage. Another important issue in EST problem is photovoltaic (PV) and nominal discharge current (Nair \& Garimella, 2009).

The above-mentioned energy system problem is often examined under EST problem. A decision on this problem is often arrived at under techno-economic requirements. The evaluation of energy system problem from this perspective excludes end-users requirements (system availability, safety, reliability, effectiveness and flexibility). This has created a knowledge gap in energy decision problem, as there is sparse knowledge on how to blend customers' and techno-economic requirements together in making an informed decision for energy storage problem. This gap motivates the need for the current paper which seeks to resolve the issue of EST selection for a small-scale renewable energy project. In trying to achieve this study aim, the importance of customers' and techno-economic requirements for EST was determined. Thus, this study presents a framework that combines FQFD (fuzzy quality function deployment), PROMETHEE (Preference Ranking Organization METHod for Enrichment of Evaluations) and TOPSIS (Technique for Order of Preference by Similarity to Ideal Solution) methods as a solution method for the above-mentioned problem.

\section{Methodology}

Decisions on multi-criteria analysis in energy study are spread in different journals that promote the need for clean energy (Akinbulire et al., 2014; Mardani et al., 2016; Ighravwe \& Babatunde, 2018). Thus, the concept of multi-criteria analysis is now been extended to EST selection problem. To achieve this task, this study's methodologyan combined a FQFD model and a PROMETHEE model. The FQFD model is used to determine the importance of the criteria that are used to select suitable batteries technology for small-scale renewable energy systems. Customers' requirements such as system availability, reliability and effectiveness are considered in the design of a FQFD model. The model is used to determine the importance of technical criteria for EST selection. A PROMETHEE model is

used to combine the values of different criteria with respect to a particular EST. Details on FQFD and PROMETHEE methods are presented as follow:

\subsection{QFD method}

The ability of QFD to combine customers' and technical requirements for a decision problem has made it a useful tool in among researchers and practitioners across the globe. QFD method has enjoyed the benefit of being integrated with other multi-criteria tools such as AHP (Tavana et al., 2017), TOPSIS 
(Chen \& Weng, 2006; Kumaraswamy et al., 2011; Li et al., 2014) and PROMETHEE (Roghanian \& Alipour, 2014). This tool considers customers' and technical requirements during the decision-making process (Roghanian \& Alipour, 2014). Its structure has also been extended to incorporate fuzzy logic (Bottani, 2009; Wang \& Chin, 2011; Raissi et al., 2012; Khandan et al., 2017).

The incorporation of fuzzy logic into QFD structure has helped to capture linguistic relationships between and among the technical and customers' requirements; this is often achieved using fuzzy (triangular and trapezoidal) numbers. Based on standard mathematical expressions in literature, fuzzy numbers are converted into crisp values. In this study, the fuzzy numbers for technical and customers' requirements are combined arithmetically using one-to-one mapping (Eq. 1). These numbers are converted into crisp values using Eq. (2).

$$
\begin{aligned}
& a_{1 k}, b_{i k}, c_{1 k}=\frac{1}{2}\left(\sum_{l=1}^{2} a_{i l k}, \sum_{l=1}^{2} b_{i l k}, \sum_{l=1}^{2} c_{i l k}\right), \\
& v_{i k}=\frac{a_{i k}+2 b_{i k}+c_{i k}}{4} .
\end{aligned}
$$

The absolute value for the techno-economic requirements from decision-makers is expressed as Eq. (3), while Eq. (4) gives the relative importance of techno-economic requirements. And the aggregated relative importance of a techno-economic requirement is given as Eq. (5).

$$
\begin{aligned}
& v_{j k}=\sum_{l=1}^{L} v_{j l k}, \\
& w_{j k}=\frac{v_{j k}}{\sum_{j=1}^{n} v_{j k}} \\
& w_{j}=\frac{1}{K} \sum_{k=1}^{K} w_{j k} .
\end{aligned}
$$

\subsection{PROMETHEE method}

Several studies have explored the potential of PROMETHEE method in addressing decision-making problem (Macharis et al., 2004; Anand \& Kodali, 2008; Roghanian \& Alipour, 2014). It has been reported that the results from some of the applications of PROMETHEE method were consistent with other multi-criteria methods such as TOPSIS and MOORA. This method shares some attributes with other multi-criteria methods. For example, it uses normalised data to make a decision. Normalised data are generated for both cost and benefit-based requirements. In order to pass-by consideration for cost and benefit-based requirements during a PROMETHEE method implementation, Eq. (6) is considered as a normalisation expression. The normalised datasets are used to generate preference function values.

$$
r_{i j}=\frac{x_{i j}}{\sqrt{\sum_{j=1}^{n} x_{i j}}} .
$$

In this study, a V-shape criterion is considered as the preference function, that is Eq. (7), for the PROMETHEE method (Y1ldırım \& Önder, E, 2014). Based on the preference function, the degree to which a requirement with respect to alternative $i$ is preferred to other alternatives' requirements values is determined using Eq. (8), while Eq. (9) expressed the degree to which alternative $k$ requirement is preferred to other alternatives' requirements values (Y1ldırım \& Önder, 2014). 


$$
\begin{aligned}
& p_{j}= \begin{cases}0 & |d| \leq q \\
\frac{|d|-q}{p-q} & q \leq|d| \leq p, \\
1 & |d| \geq p\end{cases} \\
& \pi\left(S_{i}, S_{k}\right)=\sum_{j=1}^{n} p_{j}\left(S_{i}, S_{k}\right) w_{j} \quad \forall S_{i}, S_{k} \quad i \neq k, \\
& \pi\left(S_{k}, S_{i}\right)=\sum_{j=1}^{n} p_{j}\left(S_{k}, S_{i}\right) w_{j} \quad \forall S_{i}, S_{k} \quad i \neq k .
\end{aligned}
$$

An alternative's positive flow value is determined using Eq. (10), while Eq. (11) is used to determine an alternative's negative flow value (Roghanian \& Alipour, 2014). The net flow of an alternative is given as the difference between its positive and negative flows (Eq. 12).

$$
\begin{aligned}
& \phi_{s}^{+}\left(S_{i}, S_{k}\right)=\sum_{j=1}^{n} \pi_{j}\left(S_{i}, S_{k}\right), \\
& \phi_{s}^{-}\left(S_{k}, S_{i}\right)=\sum_{j=1}^{n} \pi_{j}\left(S_{k}, S_{i}\right), \\
& \phi_{s}=\phi_{s}^{+}-\phi_{s}^{-} .
\end{aligned}
$$

where $\phi_{s}$ denotes the net flow for alternative $s, \phi_{s}^{+}$denotes the positive flow for alternative $s$ and $\phi_{s}^{-}$ denotes the negative flow for alternative $s$.

\subsection{TOPSIS method}

The scope of TOPSIS application in decision making studies has increased over the years. This is due to its simplified structure and its ability to consider and analyse linguistic information (Shamai \& Mousavand, 2011; Bagheria et al., 2018; Ighravwe \& Babatunde, 2018). This method uses a four-step based approach to determine alternatives ranks. First, this normalisation of data is carried out with respect to a requirement orientation- cost or benefit. During data normalisation, TOPSIS literature has revealed that Eq. (6) is among the frequently used expression for this purpose. However, a different expression is considered during the evaluation of linguistic variables. This entails the consideration of the desired values for a variable. The normalisation of variables is required in order to ensure that the values in a decision-matrix lie between 0 and 1 . This is necessary in order to eliminate the influence of variables with high values on the final outcome of a decision-making process.

Based on the normalised values in a decision-matrix, a weighted normalised decision-matrix is designed using the importance of the requirements in the decision matrix (Eq. 12) and this represents the second stage of in the method. Different approaches have been used to determine requirements weight during the implementation of a TOPSIS method (Sun \& Ouyang, 2015). The third stage deals with the evaluation of the alternatives solutions from the ideal positive and negative solutions. This step can be implemented using the expressions in Eq. (13) to Eq. (16).

$$
\begin{aligned}
& \bar{r}_{i j}=w_{j} r_{i j}, \\
& d_{i}^{+}=\sqrt{\sum_{j=1}^{n}\left(\bar{r}_{i j}-r_{j}^{+}\right)^{2}}, \\
& d_{i}^{-}=\sqrt{\sum_{j=1}^{n}\left(\bar{r}_{i j}-r_{j}^{-}\right)^{2}}, \\
& r_{j}^{+}=\max _{j} \forall \bar{r}_{i j} \in B, \min _{j} \forall \bar{r}_{i j} \in C,
\end{aligned}
$$




$$
r_{j}^{-}=\min _{j} \forall \bar{r}_{i j} \in B, \max _{j} \forall \bar{r}_{i j} \in C,
$$

where $B$ and $C$ are a benefit and cost-based requirements, respectively, and $d_{i}^{+}$and $d_{i}^{-}$denotes the distance of alternative $i$ from the positive and negative ideal solutions, respectively.

The results from Eqs. (13) and (14) are considered at the fourth stage. At this stage, the alternatives closeness coefficients are generated using Eq. (17) and the alternative with the highest closeness coefficient is considered as the most suitable alternative for any selection problem.

$$
d_{i}=\frac{d_{i}^{-}}{d_{i}^{+}+d_{i}^{-}}
$$

\section{Case study}

The proposed framework was tested based on information obtained from primary and secondary sources - experts and literature (Garimella \& Nair, 2009). Information from experts' was obtained using a well-structured questionnaire. The information was used to evaluate the importance of customers' requirements and their relationship with eleven techno-economic requirements (Garimella \& Nair, 2009). System availability $\left(R_{1}\right)$, reliability $\left(R_{2}\right)$, effectiveness $\left(R_{3}\right)$, safety $\left(R_{4}\right)$ and flexibility $\left(R_{5}\right)$ were considered as customers' requirements, while the techno-economic requirements in Table during the EST selection. This case study considered Lead-Acid $\left(\mathrm{S}_{1}\right)$, Nickel Cadmium $\left(\mathrm{S}_{2}\right)$, Nickel Metal Hydride $\left(\mathrm{S}_{3}\right)$ and Lithium-Ion $\left(\mathrm{S}_{4}\right)$ as potential EST for small-scale renewable energy project (Garimella and Nair, 2009). Mathematically, this decision problem is expressed as Eq. (18). The customers' and technoeconomic requirements importance in Eq. (18) were evaluated using the linguistic expressions in Table 2 .

$$
D=\left[\begin{array}{l}
s_{1} \\
s_{2} \\
\vdots \\
s_{m}
\end{array}\right]\left[\begin{array}{l}
c_{11} \cdots c_{1 m} \\
\\
c_{21} \cdots c_{2 m} \\
\vdots \\
c_{1 m} \cdots c_{n m}
\end{array}\right] .
$$

\section{Table 1}

Techno-economic data for EST (Garimella \& Nair, 2009)

\begin{tabular}{lccccc}
\hline Techno-economic requirements & & $\mathrm{S}_{1}$ & $\mathrm{~S}_{2}$ & $\mathrm{~S}_{3}$ & $\mathrm{~S}_{4}$ \\
\hline Nominal Voltage $(\mathrm{v})$ & $\mathrm{C}_{1}$ & 12 & 12 & 12 & 10.8 \\
Nominal discharge current $(\mathrm{A})$ & $\mathrm{C}_{2}$ & 20 & 10 & 20 & 43 \\
Time to reach nominal voltage $(\mathrm{hr})$ & $\mathrm{C}_{3}$ & 6800 & 4500 & 3700 & 4000 \\
Peak measured voltage $(\mathrm{v})$ & $\mathrm{C}_{4}$ & 13.5 & 13.7 & 14.1 & 11.7 \\
Max. power $(\mathrm{W})$ & $\mathrm{C}_{5}$ & 306.5 & 307 & 314 & 270 \\
PV $(\mathrm{kW})$ & $\mathrm{C}_{6}$ & 4 & 3 & 3 & 4 \\
No. of batteries & $\mathrm{C}_{7}$ & 20 & 24 & 24 & 30 \\
Converter $(\mathrm{kW})$ & $\mathrm{C}_{8}$ & 1.3 & 2 & 2 & 1.3 \\
Initial capital $(\$)$ & $\mathrm{C}_{9}$ & 31814 & 42267 & 39987 & 54654 \\
Operating cost $(\$ /$ Year) & $\mathrm{C}_{10}$ & 1137 & 991 & 1001 & 772 \\
COE $(\$ / \mathrm{kWh})$ & $\mathrm{C}_{11}$ & 1.13 & 1.36 & 1.31 & 1.62 \\
\hline
\end{tabular}


Table 2

Linguistic terms and the associated fuzzy numbers

\begin{tabular}{ll}
\hline Linguistic terms & Fuzzy numbers \\
\hline Highly unimportant (HU) & $(0,1,2)$ \\
Unimportant (U) & $(2,3,4)$ \\
Important (I) & $(4,5,6)$ \\
Very important (VI) & $(6,7,8)$ \\
Extremely important (EI) & $(8,9,10)$ \\
\hline
\end{tabular}

Looking at the information in Table 3, it shows that the first and the second decision-makers ranked the customers' requirements importance as the same (Table 3). To implement the FQFD model, this information was combined with the linguistic relationships among the customers' and technical requirements (Table 4).

Table 3

The experts' linguistic expressions for the customers' requirements importance

\begin{tabular}{lccc}
\hline Customers' requirements & $\mathrm{D}_{1}$ & $\mathrm{D}_{2}$ & $\mathrm{D}_{3}$ \\
\hline Availability & VI & VI & EI \\
Reliability & VI & VI & EI \\
Effectiveness & VI & VI & EI \\
Safety & VI & VI & EI \\
Flexibility & I & I & I \\
\hline
\end{tabular}

Table 4

Expert's judgment for the customers' requirements and techno-economic requirements

\begin{tabular}{|c|c|c|c|c|c|c|c|c|c|}
\hline \multirow[t]{2}{*}{ Requirements } & $\mathrm{D}_{1}$ & $\mathrm{D}_{2}$ & $\mathrm{D}_{3}$ & $\mathrm{D}_{1}$ & $\mathrm{D}_{2}$ & $\mathrm{D}_{3}$ & $\mathrm{D}_{1}$ & $\mathrm{D}_{2}$ & $\mathrm{D}_{3}$ \\
\hline & \multicolumn{3}{|c|}{ Availability } & \multicolumn{3}{|c|}{ Reliability } & \multicolumn{3}{|c|}{ Effectiveness } \\
\hline $\mathrm{C}_{1}$ & I & I & VI & I & I & I & I & I & I \\
\hline $\mathrm{C}_{2}$ & I & I & VI & I & I & I & I & I & I \\
\hline $\mathrm{C}_{3}$ & I & I & I & I & I & $\mathrm{U}$ & I & I & $\mathrm{U}$ \\
\hline $\mathrm{C}_{4}$ & I & I & VI & I & I & $\mathrm{U}$ & I & I & $\mathrm{HU}$ \\
\hline $\mathrm{C}_{5}$ & I & I & VI & I & I & I & I & I & $\mathrm{U}$ \\
\hline $\mathrm{C}_{6}$ & I & I & I & I & I & EI & I & I & VI \\
\hline $\mathrm{C}_{7}$ & I & I & VI & I & VI & VI & I & I & VI \\
\hline $\mathrm{C}_{8}$ & I & I & VI & VI & I & I & I & I & I \\
\hline $\mathrm{C}_{9}$ & VI & VI & VI & I & VI & $\mathrm{U}$ & I & I & I \\
\hline $\mathrm{C}_{10}$ & VI & VI & $\mathrm{U}$ & VI & VI & $\mathrm{U}$ & I & I & $\mathrm{U}$ \\
\hline \multirow[t]{2}{*}{$\mathrm{C}_{11}$} & VI & VI & $\mathrm{U}$ & VI & VI & $\mathrm{U}$ & I & I & $\mathrm{U}$ \\
\hline & \multicolumn{3}{|c|}{ Safety } & \multicolumn{3}{|c|}{ Flexibility } & & & \\
\hline $\mathrm{C}_{1}$ & VI & VI & $\mathrm{HU}$ & I & I & VI & & & \\
\hline $\mathrm{C}_{2}$ & VI & VI & $\mathrm{HU}$ & I & I & $\mathrm{U}$ & & & \\
\hline $\mathrm{C}_{3}$ & I & I & $\mathrm{HU}$ & I & I & VI & & & \\
\hline $\mathrm{C}_{4}$ & VI & VI & I & I & I & I & & & \\
\hline $\mathrm{C}_{5}$ & VI & VI & $\mathrm{HU}$ & I & I & VI & & & \\
\hline $\mathrm{C}_{6}$ & I & I & $\mathrm{HU}$ & I & I & I & & & \\
\hline $\mathrm{C}_{7}$ & VI & I & I & I & I & $\mathrm{U}$ & & & \\
\hline $\mathrm{C}_{8}$ & VI & I & HU & I & I & VI & & & \\
\hline $\mathrm{C}_{9}$ & I & I & $\mathrm{HU}$ & I & I & $\mathrm{U}$ & & & \\
\hline $\mathrm{C}_{10}$ & I & I & HU & I & I & $\mathrm{U}$ & & & \\
\hline $\mathrm{C}_{11}$ & I & $\mathrm{I}$ & $\mathrm{HU}$ & I & I & $\mathrm{U}$ & & & \\
\hline
\end{tabular}


Based on the experts' judgments, none of the techno-economic requirement importance was the same. While the first expert ranked the least and most important requirements as COE and initial capital, respectively, $\mathrm{COE}$ and $\mathrm{PV}$, converter and initial capital are ranked the least and best requirements, respectively, by the second expert (see Table 5). The third expert ranked the least and most important requirments as $\mathrm{COE}$ and nominal voltage, respectively. The aggregated values of the importance of the techno-economic requirements are presented in Table 5. The results in Table 5 showed that the least importance techno-economic requirement was COE, while nominal voltage and maximum power were the most important requirements for EST selection. When the information in this table was combined with the information in Table 6, an aggregated performance matrix was generated for the evaluation process (Table 7). To digress a little bit, it should be noted that the normalised datasets in Table 6 were based on the information in Table 1. Moving further, the alternatives' PROMETHEE values, for positive, negative, and net flows, were generated based on the information in Table 7 . And the results obtained showed that while $\mathrm{S}_{1}$ was the last-ranked EST, $\mathrm{S}_{4}$ was the highest-ranked EST (Table 8).

\section{Table 5}

Expert's judgment for the techno-economic requirements importance

\begin{tabular}{lcccc}
\hline Requirement & $\mathrm{D}_{1}$ & $\mathrm{D}_{2}$ & $\mathrm{D}_{3}$ & Aggregated weight \\
\hline $\mathrm{C}_{1}$ & 0.0869 & 0.0881 & 0.1239 & 0.0997 \\
$\mathrm{C}_{3}$ & 0.0921 & 0.0923 & 0.0853 & 0.0899 \\
$\mathrm{C}_{3}$ & 0.0921 & 0.0923 & 0.0797 & 0.088 \\
$\mathrm{C}_{4}$ & 0.0869 & 0.0881 & 0.086 & 0.087 \\
$\mathrm{C}_{5}$ & 0.0921 & 0.0923 & 0.1148 & 0.0997 \\
$\mathrm{C}_{6}$ & 0.0921 & 0.0965 & 0.105 & 0.0978 \\
$\mathrm{C}_{7}$ & 0.0921 & 0.0881 & 0.098 & 0.0927 \\
$\mathrm{C}_{8}$ & 0.0921 & 0.0923 & 0.105 & 0.0965 \\
$\mathrm{C}_{9}$ & 0.1025 & 0.0965 & 0.0853 & 0.0948 \\
$\mathrm{C}_{10}$ & 0.0973 & 0.0965 & 0.0664 & 0.0867 \\
$\mathrm{C}_{11}$ & 0.0737 & 0.077 & 0.0505 & 0.0671 \\
\hline
\end{tabular}

Table 6

Normalised values of the EST

\begin{tabular}{lcccc}
\hline \multicolumn{1}{c}{ Requirements } & $\mathrm{S}_{1}$ & $\mathrm{~S}_{2}$ & $\mathrm{~S}_{3}$ & $\mathrm{~S}_{4}$ \\
\hline $\mathrm{C}_{1}$ & 0.5123 & 0.5123 & 0.5123 & 0.4611 \\
$\mathrm{C}_{2}$ & 0.3815 & 0.1907 & 0.3815 & 0.8201 \\
$\mathrm{C}_{3}$ & 0.6934 & 0.4588 & 0.3773 & 0.4079 \\
$\mathrm{C}_{4}$ & 0.5082 & 0.5157 & 0.5308 & 0.4404 \\
$\mathrm{C}_{5}$ & 0.5111 & 0.5119 & 0.5236 & 0.4502 \\
$\mathrm{C}_{6}$ & 0.5657 & 0.4243 & 0.4243 & 0.5657 \\
$\mathrm{C}_{7}$ & 0.4039 & 0.4847 & 0.4847 & 0.6058 \\
$\mathrm{C}_{8}$ & 0.3854 & 0.5929 & 0.5929 & 0.3854 \\
$\mathrm{C}_{9}$ & 0.3702 & 0.4919 & 0.4653 & 0.6360 \\
$\mathrm{C}_{10}$ & 0.5778 & 0.5036 & 0.5087 & 0.3923 \\
$\mathrm{C}_{11}$ & 0.4135 & 0.4977 & 0.4794 & 0.5928 \\
\hline
\end{tabular}

Table 7

Aggregated preference performance matrix

\begin{tabular}{lcccc}
\hline Technology & $\mathrm{S}_{1}$ & $\mathrm{~S}_{2}$ & $\mathrm{~S}_{3}$ & $\mathrm{~S}_{4}$ \\
\hline $\mathrm{S}_{1}$ & 0.0000 & 0.0580 & 0.0476 & 0.0583 \\
$\mathrm{~S}_{2}$ & 0.0454 & 0.0000 & 0.0097 & 0.0520 \\
$\mathrm{~S}_{3}$ & 0.0442 & 0.0201 & 0.0000 & 0.0504 \\
$\mathrm{~S}_{4}$ & 0.0954 & 0.1350 & 0.0910 & 0.0000 \\
\hline
\end{tabular}




\section{Table 8}

PROMETHEE outputs for the EST ranking

\begin{tabular}{lcccc}
\hline Technology & $\phi^{+}$ & $\phi^{-}$ & $\phi$ & Rank \\
\hline $\mathrm{S}_{1}$ & 0.1639 & 0.1850 & -0.0211 & 4 \\
$\mathrm{~S}_{2}$ & 0.1071 & 0.2131 & -0.106 & 3 \\
$\mathrm{~S}_{3}$ & 0.1147 & 0.1483 & -0.0336 & 2 \\
$\mathrm{~S}_{4}$ & 0.3214 & 0.1607 & 0.1607 & 1 \\
\hline
\end{tabular}

Based on the information in Table 5 and Table 6, the TOPSIS method, that was discussed in Section 3.3, was used to generate the closeness coefficient for the EST (Table 9). The results obtained showed that the most suitable EST from the TOPSIS and PROMETHEE methods using positive and net flows results (Tables 8 and 9), while the TOPSIS and the negative flow results for the most suitable EST were not the same (see Table 8 and Table 9).

Table 9

TOPSIS outputs for the EST ranking

\begin{tabular}{lcccc}
\hline Technology & $d_{i}^{+}$ & $d_{i}^{-}$ & $d_{i}$ & Rank \\
\hline $\mathrm{S}_{1}$ & 0.0528 & 0.0439 & 0.4539 & 3 \\
$\mathrm{~S}_{2}$ & 0.0630 & 0.0335 & 0.3468 & 4 \\
$\mathrm{~S}_{3}$ & 0.0471 & 0.0434 & 0.4797 & 2 \\
$\mathrm{~S}_{4}$ & 0.0383 & 0.0670 & 0.6361 & 1 \\
\hline
\end{tabular}

\section{Conclusions}

This study has presented a framework for selecting an EST for small-scale renewable energy projects. The applicability of the framework was demonstrated using primary and secondary datasets. The results obtained from the framework provided several insights into the EST problem. One of the insights is that it showed that customers' requirements should be considered during the evaluation of EST. This is because experts' opinions affect the choice of the most suitable EST for a system. Another insight is that subjective- fuzzy logic- approach can be used to determine the importance of EST selection requirements. One of the limitations of this study is that its results are subject to change when the EST selection requirements importance change. Another limitation is that it did not consider the social and environmental requirements of the system for which the EST will be used to provide constant power supply.

Looking at these limitations, it is expected that future energy studies on this matter should take into consideration requirements that go beyond techno-economic issues. Also, further research in energy service and generation is needed; even though there are plethora researches on energy storage (Maharjan et al., 2009; Sioshansi et al., 2009; Koohi-Kamali et al., 2013). While the former- energy service problems- is expected to cover issues such as the energy tariff, business model and energy demand side, the latter- generation problems- is expected to cover issues such as feed-in tariff, operation and maintenance cost, and levelised cost of energy. If these issues are incorporated into the current framework, it will make it to be a robust decision support tool for EST problem. Also, it would be interesting if some of the data for such a model are generated using either optimisation models or simulation models. This will provide information for scenario-based analysis when dealing with EST problem. 


\section{References}

Akinbulire, T.O., Oluseyi, P.O. \& Babatunde, O.M. (2014). Techno-economic and environmental evaluation of demand-side management techniques for rural electrification in Ibadan, Nigeria. International Journal of Energy and Environmental Engineering, 5(4), 375-385.

Anand, G. \& Kodali, R. (2008). Selection of lean manufacturing systems using the PROMETHEE. Journal of Modelling in Management, 3(1), 40-70.

Baker, J. (2008). New technology and possible advances in energy storage. Energy Policy, 36, 43684373.

Bagheria, M., Shojaei, P. \& Khorami, M.T. (2018). A comparative survey of the condition of tourism infrastructure in Iranian provinces using VIKOR and TOPSIS. Decision Science Letters. 7, 87-102.

Bottani, E. (2009). A fuzzy QFD approach to achieve agility. International Journal of Production Economics, 119, 380-391.

Chen, L.H. and Weng, M.C. (2006). An evaluation approach to engineering design in QFD processes using fuzzy goal programming models. European Journal of Operational Research, 172(1), 230248.

Denholm, P. \& Sioshansi, R. (2009). The value of compressed air energy storage with wind in transmission-constrained electric power systems. Energy Policy, 37, 3149-3158.

Divya, K.C. \& Ostergaard, J. (2009). Battery energy storage technology for power systems-An overview. Electric Power Systems Research, 79, 511-520.

Ekman, C.K. \& Jensen, S.H. (2010). Prospects for large scale electricity storage in Denmark. Energy Conversion and Management, 51(6), 1140-1147.

Garimella, N. \& Nair, N.K.C. (2009). Assessment of battery energy storage systems for small-scale renewable energy integration. In IEEE TENCON 2009-2009 IEEE Region 10 Conference (pp. 1-6). IEEE

Hadjipaschalis, I., Poullikkas, A. \& Efthimiou, V. (2009). Overview of current and future energy storage technologies for electric power applications. Renewable and Sustainable Energy Reviews, $13,1513-1522$.

Ighravwe, D.E., \& Babatunde, M.O. (2018). Selection of a mini-grid business model for developing countries using CRITIC-TOPSIS with interval type-2 fuzzy sets. Decision Science Letters, 7(4), 427-442.

Janaki, D., Izadbakhsh, H., \& Hatefi, S. (2018). The evaluation of supply chain performance in the Oil Products Distribution Company, using information technology indicators and fuzzy TOPSIS technique. Management Science Letters, 8(8), 835-848.

Kaldellis, J.K., Zafirakis, D. \& Kavadias, K. (2009). Techno-economic comparison of energy storage systems for island autonomous electrical networks. Renewable and Sustainable Energy Reviews, 13(2), 378-392.

Khandan, M., Vosoughi, S., Azrah, K., Poursadeghiyan, M., \& Khammar, A. (2017). Decision making models and human factors: TOPSIS and ergonomic behaviors (TOPSIS-EB). Management Science Letters, 7(2), 111-118.

Koohi-Kamali, S., Tyagi, V.V. Rahim, N.A. Panwar, N.L. \& Mokhlis, H. (2013). Emergence of energy storage technologies as the solution for reliable operation of smart power systems: A review. Renewable Sustainable Energy Review, 25, 135-165.

Kumaraswamy, A.H., Bhattacharya, A., Kumar, V. and Brady, M. (2011, September). An integrated QFD-TOPSIS methodology for supplier selection in SMEs. In Computational Intelligence, Modelling and Simulation (CIMSiM), 2011 Third International Conference on (pp. 271-276). IEEE.

Li, M., Jin, L. \& Wang, J. (2014). A new MCDM method combining QFD with TOPSIS for knowledge management system selection from the user's perspective in intuitionistic fuzzy environment. Applied soft computing, 21, 28-37.

Macharis, C., Springael, J., De Brucker, K. \& Verbeke, A. (2004). PROMETHEE and AHP: The design of operational synergies in multi-criteria analysis: Strengthening PROMETHEE with ideas of AHP. European Journal of Operational Research, 153(2), 307-317. 
Maharjan, L., Inoue, S. Akagi, H. \& Asakura, J. (2009). State-of-charge (SOC)-balancing control of a battery energy storage system based on a cascade PWM converter. IEEE Transactions Power Electronics, 24(6), 1628-1636.

Mardani, A., Zavadskas, E.K., Streimikiene, D., Jusoh, A., Nor, K.M. \& Khoshnoudi, M., (2016). Using fuzzy multiple criteria decision making approaches for evaluating energy saving technologies and solutions in five star hotels: A new hierarchical framework. Energy, 117, 131-148.

Nair, N-K.C. \& Garimella, N. (2010). Battery energy storage systems: Assessment for small-scale renewable energy integration. Energy and Buildings, 42, 2124-2130.

Raissi, S, Izadi, M. \& Saati, S. (2012). Prioritizing engineering characteristic in QFD using fuzzy common set of weight. American Journal of Scientific Research, 49, 34-49.

Roghanian, E. \& Alipour, M. (2014). A fuzzy model for achieving lean attributes for competitive advantages development using AHP-QFD-PROMETHEE. Journal of Industrial Engineering International, 10(3), 68.

Sebastian, R. (2013). Reverse power management in a wind diesel system with a battery energy storage. Electric Power Energy System, 44(1), 160-167.

Shamai, A. \& Mousavand, J. (2011). Classification of cities of Isfahan province in view point of tourism infrastructure by using TOPSIS and AHP models. Urban-Regional Studies and Research Journal, 3(10), 23-40.

Shively, D., Gardner, J. Haynes, T. and Ferguson, J. (2008). Energy Storage Methods for Renewable Energy Integration and Grid Support. In IEEE Energy 2030 Conference, ENERGY, (pp. 1-6).

Singh, M., Lopes, L.A.C. \& Ninad, N.A. (2015). Grid forming Battery Energy Storage System (BESS) for a highly unbalanced hybrid mini-grid. Electric Power Systems Research, 127, 126-133.

Sioshansi, R., Denholm, P., Jenkin, T. \& Weiss, J. (2009). Estimating the value of electricity storage in PJM: Arbitrage and some welfare effects. Energy Economics, 31, 269-277.

Smith, S.C., Sen, P.K. \& Kroposki, B. (2008). Advancement of energy storage devices and applications in electrical power system. In IEEE Power and Energy Society General Meeting - Conversion and Delivery of Electrical Energy in the 21st Century, 2008, (pp. 1-8).

Sun, Q. \& Ouyang, J. (2015). Hesitant fuzzy multi-attribute decision making based on TOPSIS with entropy-weighted method. Management Science and Engineering, 9(3), 1-6.

Tlig, H., \& Rebai, A. (2017). A TOPSIS method based on intuitionistic fuzzy values: a case study of North African airports. Management Science Letters, 7(7), 351-358.

Walawalkar, R., Apt, J. \& Mancini, R. (2007). Economics of electric energy storage for energy arbitrage and regulation in New York. Energy Policy, 35, 2558-2568.

Wang, Y.M.. \& Chin, K.S. (2011). Technical importance ratings in fuzzy QFD by integrating fuzzy normalisation and fuzzy weighted average. Computer Math Applications, 62, 4207-4221.

Y1ldırım, B., \& Önder, E. (2014). Evaluating potential freight villages in Istanbul using multi criteria decision making techniques.

Zogg, R., Lawrence, T., Ofer, D. \& Brodrick, J. (2007). Distributed energy storage. ASHRAE Journal, 49,90 .

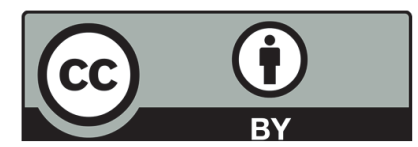

(C) 2019 by the authors; licensee Growing Science, Canada. This is an open access article distributed under the terms and conditions of the Creative Commons Attribution (CC-BY) license (http://creativecommons.org/licenses/by/4.0/). 